\title{
ANÁLISE DAS RELAÇÕES SOCIAIS ATRAVÉS DA LITERATURA DISTÓPICA
}

\section{ANALYSIS OF SOCIAL RELATIONS THROUGH DYSTOPIAN LITERATURE}

\author{
Isabella Pereira ${ }^{1}$ \\ Renata Patricia Forain de Valentim ${ }^{2}$
}

\begin{abstract}
Resumo: Após ganhar força no período pós-guerra, a literatura distópica ressurge na pós-modernidade, como discurso voltado ao público adolescente e jovem adulto. Neste artigo é feita uma revisão bibliográfica das seguintes obras de ambos os momentos históricos: 1984, Fahrenheit 451, trilogia Jogos Vorazes e trilogia Destino. Os romances foram analisados qualitativamente através da análise de conteúdo de Bardin, que identifica "unidades temáticas", elementos significantes comuns. Através das categorias "A influência social na vida privada": "Vida familiar e social" e "Vida amorosa" examina-se como se relacionam as subjetividades destes jovens com o futuro e a realidade que os cerca, como eles se identificam com as produções literárias e como estas representam o discurso produzido na sociedade em que estão inseridos.
\end{abstract}

Palavras-chave: Literatura distópica; Pós-Guerra; Pós-Modernidade; Relações sociais; Análise de conteúdo.

\begin{abstract}
After gaining strength in the post-war period, dystopian literature resurfaced in postmodernity, as a discourse aimed at the adolescent and young adult public. In this article a bibliographical revision of the following works from both historical moments is made: 1984, Fahrenheit 451, Hunger Games trilogy and Destiny trilogy. The novels were analyzed qualitatively through the content analysis of Bardin, which identifies "thematic units", significant elements in common. Through the categories "Social influence in private life": "Family and social life" and "Love life" it's examined how the youth subjectivities relate to the future and their social reality, how they identify themselves to the literary productions and how these ones represent the discourse produced in the society in which they are inserted.
\end{abstract}

Keywords: Dystopian literature; Post-war; Postmodernity; Social relations; Content analysis.

\section{Introdução}

Em nossa contemporaneidade, uma categoria literária muito presente é a distopia. E esta não é a primeira vez em que este estilo está em voga, sendo representado por exemplares já no período das grandes guerras mundiais. Agora, no início do terceiro

\footnotetext{
${ }^{1}$ Graduada em Psicologia pela Universidade do Estado do Rio de Janeiro (UERJ), Rio de Janeiro, RJ, Brasil. E-mail: isabella.pereira94@outlook.com

${ }^{2}$ Doutora em Psicologia pela Universidade Federal do Espírito Santo (UFES). Professora da Universidade do Estado do Rio de Janeiro (UERJ), Rio de Janeiro, RJ, Brasil. E-mail: renatapfvalentim@ gmail.com; renatapfvalentim@gmail.com
} 
milênio, dominando as vendas em literatura voltada para o público juvenil, em uma época chamada de Pós-Modernidade, surge a questão de por que esse discurso está sendo novamente valorizado em detrimento de outros e o que tem levado os jovens a se interessarem por ele.

A hipótese deste trabalho é a de que este enunciado distópico, teoricamente externo, relaciona-se com as formas atuais de interioridade, particularmente a juvenil. Partindo do pressuposto que o discurso nos forma e forma nossa época, podemos pensar que o tempo em que vivemos exerce grandes pressões sobre adolescentes e jovens adultos. Isto pode explicar a onda distópica voltada para o público juvenil e a identificação dos jovens com os ambientes e situações retratadas nos livros publicados nas décadas de 2000 e 2010, enquanto os da década de 1940-50 dirigem-se, majoritariamente, ao público adulto.

Para realizar esta discussão, neste trabalho serão apresentadas comparativamente as seguintes obras literárias: escritas entre as décadas de 40 e 50 temos 1984 (ORWELL, 2015) e Fahrenheit 451 (BRADBURY, 2014). Já entre as atuais, temos a trilogia Jogos Vorazes (COLLINS, 2010) e a trilogia Destino (CONDIE, 2011). As obras serão analisadas qualitativamente através da análise de conteúdo de Bardin (2016), que identifica as chamadas "unidades temáticas", elementos significantes comuns nos textos analisados.

Os dados coletados nesta pesquisa são oriundos de revisão bibliográfica. O estudo das obras literárias utilizadas tem como intenção fundamentar teoricamente o argumento e corroborar com a compreensão da questão central apresentada, abordando o retorno destas narrativas no início do século XXI e realizando um mapeamento histórico deste gênero.

Através das categorias discriminadas, serão examinadas como se relacionam as subjetividades destes jovens com o futuro e a realidade que os cerca, como eles se identificam com as produções literárias e como estas representam o discurso produzido na sociedade em que estão inseridos.

\section{Conceituando distopia}

Para entender melhor o conceito de distopia é importante primeiramente entender a utopia. Esta é caracterizada como um ideal de sociedade alternativa a que se vive, o 
sonho de uma vida melhor, mais justa, e também, na maioria das vezes, inalcançável ou imaginária.

A imaginação utópica é algo que pertence ao homem e que não pode ser retirada dele (tentativa esta empreendida em 1984, através da reeducação do protagonista do romance, seguida de sua morte), e, por isso, ela é uma ameaça aos governos totalitários. Para Coelho (1986), esta forma de imaginação é imanente ao homem e não algo germinado por acontecimentos de seu tempo (característica que neste trabalho será atribuída às distopias, visto que elas surgem como marcos literários em determinadas épocas históricas).

Coelho (1986) nos mostra ainda que não são todas as ideias trazidas à tona pela imaginação utópica que serão capazes de proporcionar vidas melhores. Em regimes totalitários como nazismo e fascismo é possível notar um plano de purificação tendo como objetivo uma sociedade em perfeito funcionamento, livre de diferenças, caracterizando um modo de pensamento utópico.

Assim, podemos perceber que a utopia nem sempre é algo bom para todos os envolvidos neste projeto, pois, por se tratarem de reformas realizadas de forma verticalizada, outorgam o controle aos poderosos e retiram da maioria da população a capacidade de decidir sobre suas vidas. Ao citar os estudos de Karl Popper, Coelho ilustra um dos motivos para os traços distópicos nas utopias:

\footnotetext{
é que elas seriam resultado de uma vontade subjetiva, de um desejo individual incapaz de levar em conta as reais necessidades e desejos das pessoas às quais os projetos utópicos se destinariam. Isso provocaria inevitavelmente aquelas distorções, por mais bem intencionado que fosse o autor (COELHO, 1986, p. 47).
}

De acordo com Hilário, "Etimologicamente, distopia é palavra formada pelo prefixo dis (doente, anormal, dificuldade ou mal funcionamento) mais topos (lugar). Num sentido literal, significa forma distorcida de um lugar" (2013, p. 205).

\footnotetext{
a utopia ganha um caráter positivo, de evolução para a felicidade humana geral, enquanto que a distopia está ligada ao inverso, ao poder de poucos e à felicidade de poucos, sendo que a maioria ou é eliminada ou é alienada (WOJCIEKOWSKI, 2009, p. 27).
}

A definição de distopia não é unânime para seus estudiosos. Por um lado, a distopia pode ser entendida como uma "utopia negativa", à medida que propõe ao leitor que reconsidere seus paradigmas, posicionando-o frente a um panorama drástico e por vezes maniqueísta (PAVLOSKI, 2005). Outros autores, porém, compreendem justamente o contrário, que utopia e distopia não se opõem, pois a última não é avessa à primeira e 
não a descarta, mas sim distorce acontecimentos presentes para problematizá-los (HILÁRIO, 2013).

Já segundo Coelho (1986), "distopia" não pode ser o contrário de "utopia”, pois este seria "topos", um lugar concreto e real. Neste trabalho, a partir dos romances estudados, abordaremos o conceito de distopia como uma falsa utopia, uma vez que estes, em sua maioria, apresentam suas sociedades como aparentemente boas e perfeitas, escondendo esquemas de controle por detrás de um governo autoritário.

As primeiras obras distópicas surgiram no início do século $\mathrm{XX}$, em um período marcado pelas grandes guerras mundiais e o momento entre elas, um momento marcado pela expansão industrial, imperialista e bélica, o homem encontrava-se com esperanças acerca dos rumos tecnológicos em curso. Mas esta esperança logo é suplantada à medida que fatores como a fome e a guerra não são erradicados e as indústrias servem para aumentar mais a exploração sofrida, além da grande repressão estatal (FROMM, 2015).

A distopia caracteriza-se fortemente por denúncias a estas relações desiguais de poder, onde há um grande controle de informações e da própria população. Para Silva (2014), este grande monitoramento faz crer que as regras aplicadas são para o bem comum, mas encobrem a manipulação ideológica e distorção da realidade, que normalmente não advém de um inimigo único, mas todo um sistema, o que impacta os leitores, encarregando-os de desesperança ou do ímpeto de mudança.

Através do controle e da disciplina impostos desenrola-se também um processo de assujeitamento, pois nas distopias não só os sistemas dominantes produzem os sujeitos como os condicionam da forma que melhor os aprouver, sem que estes tenham noção disso, de forma que aceitam passivamente este controle como forma de cuidado. Este condicionamento interioriza as pressões sociais e, embora se apresente de forma exagerada na literatura, não está muito distante de nosso mundo atual (HILÁRIO, 2013).

\footnotetext{
Desta maneira, os sujeitos não apenas se inscrevem no tecido social através de práticas culturais, mas também são produzidos a partir de determinada sociedade de maneira dialética. Na modernidade, inicia-se o processo de produção do sujeito regulado pela dinâmica social, em perpétuo movimento de transformação (HILÁRIO, 2013 p. 207).
}

Torna-se relevante destacar que a distopia compõe um gênero da literatura, mas mostra-se uma ferramenta extremamente útil para a Psicologia na medida em que se apresenta como uma lente para analisar criticamente os fenômenos sociais e a contemporaneidade. Acredita-se que, através de suas atmosferas radicais, este tipo de leitura possui como função fazer soar um alarme sobre as consequências bárbaras que 
podem vir a ocorrer se algumas ações opressoras do presente se mantiverem em prática, pois, mesmo se apresentando em caráter de ficção, comportam as questões humanas, políticas e sociais que movem tanto o autor, como o leitor (SILVA, 2014).

\subsection{Romances distópicos}

Para analisar o surgimento da literatura distópica no século XX e seu novo boom no início do século XXI é de extrema importância investigar os acontecimentos históricos que estavam em curso e que tornaram propício seu desenvolvimento.

Em um contexto de guerras e revoluções industriais, o cenário político dominado pelas disputas entre comunismo e capitalismo propicia "uma consciência menos otimista acerca do futuro" (NEUMANN; SILVA; KOPP, 2013, p. 84). É neste período da história que surgem 1984, de George Orwell (escrito em 1948 e publicado em 1949), e Fahrenheit 451, de Ray Bradbury (idealizado em 1947 e publicado pela primeira vez em 1953).

O livro 1984 (ORWELL, 2015) retrata uma sociedade comunista a-histórica centrada na figura do Grande Irmão, que tudo vê. Nenhum dos habitantes de Oceânia (local onde se passa a novela) parece se lembrar do que ocorreu antes da grande revolução que instaurou o sistema vigente, além de não possuírem um registro fixo de passado. A história está sempre em reconstrução para adequar-se às previsões feitas pelo líder e encobrir das demais pessoas os acontecimentos reais sobre a sociedade.

Formas eficientes de controle e vigilância são estabelecidas através da educação infantil, na qual, desde pequenas, crianças são ensinadas a espionar os pais e qualquer outro que possua comportamentos estranhos e denunciá-los ao Partido. Contando com dispositivos como as teletelas, aparelhos semelhantes a televisões que não só transmitem imagens como também as recebem, entre outros métodos, o Partido observa de perto cada indivíduo de modo a não permitir interações casuais e pensamentos discordantes da ideologia posta.

Winston Smith, o personagem principal, tem dúvidas sobre o sistema e sobre a ideia aceita pela maioria de que as coisas sempre foram desse modo. Ao relacionar-se com Julia, uma jovem também avessa aos princípios do Partido, ele passa a questionar mais a origem do poder de sua sociedade, bem como formas de governo alternativas a ela.

Outro romance, Fahrenheit 451 de autoria de Ray Bradbury (2014), tem sua história passada em um cenário no qual opiniões próprias são desestimuladas por não 
serem aceitas socialmente e onde livros são proibidos devido à sua periculosidade, culminando em seu extermínio pelos bombeiros. Um desses bombeiros é Guy Montag, protagonista da história, que segue a profissão de seu pai e avô e acredita estar fazendo a coisa certa ao destruir obras literárias.

Certa noite, Montag conhece sua nova vizinha, uma jovem de pensamento livre e argumentador, chamada Clarisse McClellan, que o instiga com perguntas que o levam a questionar sua felicidade, bem como sua vida e seus ideais. Ao chegar em casa e presenciar sua esposa (cujo único objetivo na vida é posicionar-se frente a uma televisão) desacordada pela ingestão de diversos comprimidos ter seu sangue substituído pela assistência médica, nosso personagem principal repensa de fato sua sociedade.

Posteriormente, ao ver em seu trabalho, uma senhora preferir ser queimada com seus livros a abandoná-los, a curiosidade de Montag aumenta em relação a esses objetos, o que o faz roubar um deles e lê-lo na clandestinidade. Ao conhecer Faber, um professor que reforça a importância da leitura, descobre a existência de um grupo de refugiados literatos que vivem às margens da cidade onde podem expressar livremente seu interesse pela literatura, até que a sociedade seja reformada e não mais precisem viver foragidos (representando, aqui, a utopia, à qual posteriormente Montag se unirá).

Abordando agora as novas distopias, aquelas surgidas no início do século XXI, é importante destacar que seu diferencial em relação àquelas produzidas no pós-guerra é o fato de que estas se voltam ao público juvenil. Elas têm como alvo, jovens entre 14 e 23 anos de sociedades ocidentais em desenvolvimento ou desenvolvidas que, em sua maioria, não experimentaram o exercício de um governo totalitário.

Após a "nova onda distópica" ser iniciada com sucesso comercial satisfatório, outras obras se seguiram, mas o êxito se sustenta, provavelmente, devido à atmosfera pessimista da pós-modernidade (SILVA, 2014). Para Neumann, Silva e Kopp (2013), fatores como divisão social, concentração de renda, controle social sobre subjetividades, exploração do trabalho humano, modos de ser hedonistas e egocêntricos, além da presença midiática como agente opressor e alienante ajudam a desenvolver o clima negativista de nosso tempo.

O romance Jogos Vorazes foi lançado em 2008 nos Estados Unidos e escrito por Suzanne Collins, que quebra um paradigma ao se lançar como autora em um círculo antes restrito aos homens. O protagonismo nesta série de três romances também é ocupado por uma mulher, Katniss Everdeen e tem como cenário um reality show homônimo ao livro. 
A saga se passa em um país chamado Panem, reerguido após diversos desastres onde antes se localizava a América do Norte, formado pela Capital, rica e tecnológica, e 13 distritos, explorados cruelmente. Insatisfeitos com os abusos sofridos, os distritos se levantaram contra a Capital, mas o fracasso desta insurreição levou à destruição do Distrito 13 e, como punição, a criação dos Jogos Vorazes, reality show onde, anualmente os doze distritos deveriam entregar dois "tributos" (um garoto e uma garota) para lutarem em uma arena na qual o último sobrevivente seria o vencedor.

A trilogia conta a história de Katniss, tributo do distrito 12, que se voluntariou para a $74^{\mathrm{a}}$ edição dos Jogos após sua irmã mais nova ter sido sorteada, tomando, assim, seu lugar. O outro tributo é Peeta Mellark, o filho do padeiro, o que lhe concede uma condição mais abastada que a maioria de seus conterrâneos. Peeta nutre sentimentos por Katniss que, por outro lado, tem com ele uma dívida que deseja pagar. Assim, forma-se uma aliança incentivada por Haymitch, seu mentor, com Peeta demonstrando o que sente e Katniss fingindo corresponder, em uma relação logo aclamada pelo público como sendo a de "dois amantes desafortunados".

Ao saírem ambos vitoriosos dos Jogos, (por pressão popular dos habitantes da Capital) uma ameaça ainda maior os aguarda: o presidente de Panem, descontente com o desprezo conferido ao seu sistema, que antes declarava que apenas uma pessoa poderia ganhar os jogos, passa a vigiá-los mais de perto. Atos rebeldes começam a pontuar os distritos, resultando em repressões cada vez mais violentas por parte da Capital, acarretando em torturas e mortes.

Já em Destino, a trilogia da autora americana Ally Condie (2011), Cassia Reyes é uma jovem de 17 anos convicta em tudo o que a Sociedade preparou para sua vida, incluindo sua profissão, a idade em que vai morrer e com quem se casará. Ao participar do Banquete do Par e conhecer seu futuro marido, ela vê que o destino reserva como par seu melhor amigo, Xander. Mas ao chegar em casa e verificar novamente seu cartão de par, quem aparece é Ky, seu antigo vizinho.

Ao perceber o que parece ser o primeiro erro da Sociedade, Cassia põe em xeque outras decisões arbitrárias sobre sua vida, e parte em busca do caminho de sua própria história. Diferentemente dos romances já citados, este livro não se trata de um mundo pós-apocalíptico, mas aborda temas como relacionamentos e livre arbítrio.

Desta forma, vemos que a "nova" distopia apresenta uma falsa utopia, organizações sociais aparentando perfeição e eficiência camuflando o controle social, tolhimento de liberdades e alienação, dominadas pela corrupção humana de modo a 
docilizar corpos (SILVA, 2014). Para Neumann, Silva e Kopp (2013), a tecnologia como modo de ser configura um temor, uma vez que todo o controle exercido sobre os destinos individuais ocorre por meio desta.

Nestas duas séries, há dois pontos principais em comum, sendo um deles o protagonismo feminino e adolescente, em oposição aos clássicos distópicos das décadas de 1940 e 1950 que apresentavam homens adultos. Para Silva (2014),

esse passou a ser um padrão, talvez porque os frequentes envolvimentos amorosos das protagonistas (sejam centrais ou não na narrativa) atraiam mais o público feminino. E isso se soma à constante presença de violência e ação, o que, de forma também estereotipada, pode trazer os leitores masculinos (p. 44).

Ainda segundo Silva (2014), outro ponto em comum entre essas obras é a presença de um mundo externo ao do poder dominante, em que vivem forças rebeldes (característica já presente nas distopias clássicas), que são representadas como o Distrito 13 em Jogos Vorazes e Insurreição em Destino. Estas comunidades alternativas são descobertas pelas personagens após constatarem a farsa que seus governos representam (embora em Jogos Vorazes, a repressão do governo seja desde o início bem clara para os cidadãos).

Analisando os processos pelos quais passam as personagens das diferentes distopias, é possível notar a presença de um rito de passagem em cada uma delas. Os Jogos Vorazes e o Banquete do Par simbolizam etapas pelas quais os adolescentes passam nessa faixa etária, não sem sacrifício (de sua infância e inocência) ou angústias.

Mesmo com a virada distópica e o surgimento de novas obras literárias, permanece o alarme de que, mantidas as condições presentes, o futuro tende apenas a se tornar mais destrutivo, questão que busca incomodar e impactar seus leitores.

\begin{abstract}
A vida se torna pior no futuro imaginado pelo autor, mesmo que, em muitos casos, seus habitantes imaginários sequer percebam isso. Essas advertências e a ideia de "pior" destacam sempre condições relacionadas ao contexto do autor, que lhe parecem indesejáveis caso elas se realizem ou se radicalizem como modo de vida. São, portanto, críticas à sociedade que contemplam aspectos sociais, políticos, econômicos e culturais (NEUMANN; SILVA; KOPP, 2013 p. 85).
\end{abstract}

\title{
3 Analisando os conteúdos
}

\subsection{Método}

Para analisar os dados coletados nesta pesquisa, foi utilizado como método a Análise de Conteúdo, apresentada e descrita por Laurence Bardin (2016). Segundo ela, 
"a análise de conteúdo aparece como um conjunto de técnicas de análise das comunicações que utiliza procedimentos sistemáticos e objetivos de descrição do conteúdo das mensagens." (BARDIN, 2016, p. 44, grifos da autora). A escolha por esse método deve-se à possibilidade que ele suscita de comparar discursos selecionando temas específicos, de modo a não estender-se sobre o conteúdo como um todo.

Neste trabalho é realizada uma análise qualitativa temática, classificando os textos estudados de acordo com aspectos comuns, dividindo-os em categorias. Como nos mostra Bardin (2016), os resultados obtidos com a análise de conteúdo permitem ilustrar os pressupostos anteriormente estabelecidos e, neste caso, a hipótese formulada da relação entre a distopia e seu contexto social.

Tendo em vista as proposições acima, pesquisou-se como se dá a produção de subjetividade na Pós-Modernidade através da lente da distopia literária e entender o retorno destas narrativas no início do século XXI, quando anteriormente, seu ápice havia sido no período de guerras mundiais. Através das categorias discriminadas, serão examinadas como se manifestam as subjetividades destes jovens tementes por seu presente e futuro, como eles se identificam com as produções literárias e como estas representam o discurso produzido na sociedade em que estão inseridos.

Considerando os romances literários analisados como meios de comunicação de massa, é possível observar uma dupla relação com seu contexto de criação. Ao mesmo tempo em que as comunicações massificadas são responsáveis por produzir e influenciar culturalmente a sociedade, elas são também influenciadas por discursos múltiplos atravessados em agenciamentos coletivos de seu contexto sócio-histórico.

Deste modo, para melhor interpretar as produções culturais de uma época é preciso dedicar-se a compreender o período histórico, ideológico e social no qual elas foram criadas (WOJCIEKOWSKI, 2009). Com as ficções científicas, gênero a qual pertencem os livros estudados neste trabalho, não é diferente, pois elas podem

\footnotetext{
ter seu cenário em futuro próximo ou distante, que é, na verdade, uma criação embasada no presente vivido no momento da sua produção - e não se tratando de um futuro real ou uma previsão deste (aquele que acontecerá, ou aconteceu, após o fim da obra e mesmo da morte dos autores - o futuro/passado concreto e Histórico) (WOJCIEKOWSKI, 2009, p. 302).
}

Considerando o atravessamento desses discursos, o escritor passa a ser destituído de sua função de autor uno da obra que produz, deixando de ser o responsável ou o produtor de seus textos. O filósofo Michel Foucault, em sua conferência apresentada à Sociedade Francesa de Filosofia em 22 de fevereiro de 1969 e, posteriormente publicada, 
intitulada "O que é um autor?", discorre sobre a lógica que atravessa os discursos de determinada época e as condições para o funcionamento dessas práticas.

O filósofo se interessa então sobre as possibilidades de produção de discurso, colocando o autor como um sujeito também delimitado por discursos. Para Foucault, a escrita ultrapassa suas próprias regras, em um processo que "não se trata da amarração de um sujeito em uma linguagem; trata-se da abertura de um espaço onde o sujeito que escreve não para de desaparecer" (FOUCAULT, 1992, p. 268).

Questiona-se como um sujeito aparece na ordem dos discursos e qual lugar cabe a ele ocupar em diferentes tipos de discursos, bem como suas funções a exercer e regras a obedecer. Deste modo retira-se o sujeito de seu papel criador e analisa-o como uma variável do discurso. Aí consiste a ideia de morte do autor: A ideia que o discurso vem do homem, do autor, morre, pois este homem também é oriundo de outros discursos (FOUCAULT, 1992).

Com o desaparecimento do autor como produtor único de sua obra, surgem como autores também os sujeitos-leitores, que atribuem diferentes sentidos aos conferidos originalmente pelo escritor, caracterizando uma leitura polissêmica, nova a cada vez que é realizada. Nesta concepção, o sujeito é assujeitado a partir de formações sociais com leis e normas exteriores a ele (WOJCIEKOWSKI, 2009).

Por isto, o objetivo deste trabalho é analisar as obras literárias já citadas anteriormente em seus aspectos sociais e ideológicos buscando exemplos nas sociedades em que se inserem. Assim, percebe-se que a literatura constitui uma forma de expressão de seu cenário de origem, representando deste modo uma comunicação de massa passível da análise de conteúdo (WOJCIEKOWSKI, 2009).

\subsection{A influência social na vida privada}

Na década de 1940, o mundo, principalmente os países ditos desenvolvidos, passa por grandes mudanças com o fim da Segunda Guerra Mundial em 1945 e a crescente industrialização, que assim como a urbanização e a revolução técnico-científica tiveram seu auge. Este período foi o chamado "moderno", que compreendeu os anos de 1916 a 1991 e composto de diversas mudanças no cenário global em um pequeno período de tempo.

Baseada nas produções em série, surgiram as práticas massivas entre a sociedade, criando sujeitos submissos e passivos dos acontecimentos políticos de seu tempo. Na 
Inglaterra de George Orwell, novas tensões surgem, ocasionadas pela destruição de bombas, racionamento de comida no período imediatamente após as guerras, e, também, o desmonte da esperança pela paz, transformado em desespero.

Neste país, através da ajuda cedida pelos Estados Unidos com o Plano Marshall, o programa de nacionalização das indústrias e reestruturação da qualidade de vida, surge um forte impulso para o consumo, assim como nos EUA de Ray Bradbury, materializado, principalmente na forma de aparelhos televisores. O contexto doméstico em quase todas as nações do Ocidente, segundo Langhamer (2005) é perpassado por ansiedades e um desejo expresso de reestabelecer a vida matrimonial e familiar, como se vê a partir do baby boom.

\subsubsection{Vida familiar e social}

Nos livros analisados do período pós-guerra, a influência do governo se dá justamente nos relacionamentos afetivos. Em 1984, por exemplo, os casamentos são mera formalidade, já que as famílias se formam com o único objetivo de procriar e gerar futuros servidores do Partido Socing (Socialista Inglês).

O único propósito reconhecido do casamento era gerar filhos para servir ao
Partido. A relação sexual devia ser encarada como uma operaçãozinha
ligeiramente repulsiva, uma espécie de lavagem intestinal. Isso tampouco era
dito com todas as letras, sendo antes inculcado sub-repticiamente na cabeça
dos membros do Partido desde a mais tenra infância. Havia inclusive
organizações que defendiam o celibato absoluto para ambos os sexos. Todas
as crianças seriam geradas por inseminação artificial (semart, em Novafala) e
criadas por instituições públicas (ORWELL, 2015, p. 84).

A ideia de "família" também se encontra alterada em Fahrenheit 451 (Bradbury, 2014). Montag leva uma vida infeliz, o que só percebe ao ser questionado por Clarisse, sua vizinha adolescente, e parte disto se deve ao seu casamento com Mildred, uma mulher que não ama.

\footnotetext{
E lembrou-se de ter pensado naquela hora que, se ela morresse, decerto ele não choraria. Pois seria a morte de uma desconhecida, um rosto da rua, uma foto do jornal e, de repente, a ideia lhe fora tão forte que ele começara a chorar, não pela morte, mas pela ideia de pensar em não chorar diante da morte, um homem ridículo e vazio junto de uma mulher ridícula e vazia, enquanto a serpente faminta a deixava ainda mais vazia.

Como uma pessoa fica tão vazia?, perguntou a si mesmo. Quem esvazia a gente? E aquela flor terrível no outro dia, aquele dente-de-leão! Aquilo havia resumido tudo, não? "Que pena! Você não está apaixonado por ninguém!" E por que não? (BRADBURY, 2014, p. 58-59).
}

Nesta obra, a televisão ocupa também uma posição central na sociedade mas, diferentemente das teletelas de 1984 , elas servem apenas para distração e alienação de 
quem a assiste. Não se trata apenas de uma "telinha", mas de telas que ocupam por completo as paredes, e, normalmente as quatro paredes de um cômodo.

Graças a este "circuito de tela múltipla" (BRADBURY, 2014, p. 29), os espectadores podem se sentir parte integrante da programação, fato que leva Mildred a considerar as pessoas ali atuantes como de sua família:

— Livros não são pessoas. Você lê e eu olho em volta, mas não há ninguém! Ele olhou para o salão, morto e cinzento como as águas de um oceano que transbordaria de vida se eles acendessem o sol eletrônico.

- Agora — disse Mildred —, minha "família" é de pessoas. Elas me contam coisas: eu rio, eles riem! E as cores, então?! (BRADBURY, 2014, p. 91).

Pouco se fala sobre relações de amizade em ambos os livros citados acima. Em 1984, este conceito parece inexistir, restando apenas a camaradagem entre os membros do partido e servidão ao Grande Irmão. Já em Fahrenheit 451, nada se diz sobre possíveis amigos de Guy Montag: vemos apenas Clarisse e Faber como seus mentores para uma vida intelectualizada e as amigas de sua esposa, que se reúnem para ver televisão. Sobre as relações sociais, Clarisse diz:

Acho que sou tudo o que dizem que sou, tudo bem. Não tenho amigos. Isso é o bastante para provar que sou anormal. Mas todos que conheço estão gritando ou dançando por aí como loucos ou batendo uns nos outros. Você já notou como as pessoas se machucam entre si hoje em dia? (BRADBURY, 2014, p. 41).

Tanto no livro de Orwell quanto no de Bradbury podemos ver as interações sociais inibidas a não ser que se desenrolem de modo a manter o status quo. Na Oceânia (ORWELL, 2015), ambiente hostil e de extrema rigidez isto é visto mais claramente, pois seu principal objetivo é esvaziar seus habitantes de modo a preenchê-los com a doutrina do partido. Já em Fahrenheit 451, os relacionamentos vazios não são resultado de práticas do governo, mas apenas ocorrência do desuso, uma vez que as pessoas não viam mais função em conversas, como relembra Montag no discurso de Clarisse:

\footnotetext{
Meu tio diz que geralmente existiam alpendres. E as pessoas às vezes se sentavam ali à noite, conversando quando queriam conversar; caladas nas cadeiras de balanço, só se balançando quando não queriam conversar. Às vezes simplesmente ficavam ali sentadas, pensando, refletindo. Meu tio diz que os arquitetos eliminaram os alpendres porque não tinham um bom aspecto. Mas meu tio diz que isso não passava de racionalização; o verdadeiro motivo, escondido por baixo, podia ser o de que não queriam as pessoas sentadas daquele jeito, sem fazer nada, balançando nas cadeiras, conversando; esse era o tipo errado de vida social. As pessoas conversavam demais. E tinham tempo para pensar. Por isso, acabaram com os alpendres. E com os jardins, também (BRADBURY, 2014, p. 82).
}

A educação formal é também vista como inútil, mas não necessariamente usada de modo a manter o povo sob controle (como em 1984), e sim porque a vida levada pelas 
pessoas a tornou obsoleta. Como Faber diz: "A vida é imediata, o emprego é que conta, o prazer está por toda parte depois do trabalho. Por que aprender alguma coisa além de apertar botões, acionar interruptores, ajustar parafusos e porcas?” (BRADBURY, 2014, p. 73).

No campo das relações sociais, em nosso tempo, perpassado por tecnologias que nos permitem uma aproximação virtual daqueles que se encontram distantes, percebe-se uma solidão contraditória através de conexões superficiais. Quanto mais conectados virtualmente, menos entra-se em contato efetivamente com o outro, de modo em que, diversas vezes, os relacionamentos se dão por trocas entre imagens construídas e não mais, sujeitos.

Curiosamente, os livros produzidos neste período apresentam relações familiares e amorosas mais permissivas e fluidas quando comparadas aos livros do pós-guerra. Em Jogos Vorazes, por exemplo, as famílias se constituem devido a sentimentos genuínos e, embora algumas normas regrem seu funcionamento, pode-se ver os laços afetivos que unem esses agrupamentos.

Na trilogia de Collins, a família é uma questão principal para Katniss: depois do falecimento de seu pai, ela passou a ser a provedora de casa. O relacionamento da personagem principal com sua irmã Prim é dotado de uma grande carga de amor e proteção, sendo esta a responsável pela inserção de Katniss nos Jogos Vorazes, uma vez que entrou como voluntaria no lugar de Prim, oferecendo, literalmente, sua vida por ela. Além disso, vemos sua amizade com Gale, seu companheiro de caça, com quem compartilha todas as suas inseguranças em relação à vida nos distritos, ao futuro e ao governo da Capital (COLLINS, 2010).

Em Destino, as relações familiares são completamente regradas pela Sociedade: os casais são "montados" no Banquete do Par e o número de filhos é previamente determinado. Mesmo assim, é possível perceber a presença de sentimentos e afetividade nas famílias, sendo nos relacionamentos entre casais ou nas relações entre pais-filhos e irmãos.

É interessante notar o papel completamente diferente desempenhado pelas famílias nos livros do século XX e nestes do século XXI. Os livros escritos no pós-guerra apresentam formações familiares meramente formais e destituídas de conexões afetivas, mesmo sendo este um período notadamente marcado pela busca da reestruturação familiar. 
Em um estudo sobre o significado do "lar" na Grã-Bretanha pós-guerra, Langhamer (2005) discorre que neste momento, lar torna-se um lugar de conforto, onde as pessoas têm suas posses, mas também nos mostra que

\begin{abstract}
An association of home with a privatized, family life was important to both men and women. For one man, home was 'the place where one is in the company of the person or people whom one loves best'. A female panellist observed that: 'You never realize what home means to you until you have founded one yourself and created a family of your own. To us it means all, security, happiness, comradeship', whilst another stated that: 'Home means the spot where I can keep my family safe and sheltered and private.' (LANGHAMER, 2005, p. 34). ${ }^{3}$
\end{abstract}

Já o século XXI é um período marcado em especial por uma "sociedade que se apresenta fragmentária e fragmentadora dos afetos e dos laços sociais, o homem da pósmodernidade se aferra ao consumo como ancoragem identitária, substitutiva das gratificações amorosas que deveriam emanar de suas relações com os demais homens" (SOARES; EWALD, 2004, p. 1-2). Apesar disto, suas distopias apresentam relações familiares mais sinceras, pois, mesmo que algumas sejam formadas forçosamente, apresentam o que, por noção geral, constitui uma família: o afeto.

Uma hipótese para essa aparente contradição é a necessidade, no contexto pósguerra de reestruturar o país economicamente (no caso da Inglaterra), ou de firmar-se como potência (no caso dos Estados Unidos), sendo para isto primordial a construção de lares e famílias, a fim de estimular e manter os padrões de consumo. Desta forma, podese compreender a ausência de afeto em algumas relações familiares e o círculo social restrito aos ambientes de trabalho, já que este era o outro lado da moeda do fortalecimento econômico, posto em prática por estes governos capitalistas.

Nos dias atuais, no período chamado de pós-modernidade, o enfoque do capital, da sociedade e das propagandas recai sobre o indivíduo, de forma que beira (e às vezes é) o egoísmo: "seja feliz”, “alcance seus sonhos”, “seja o melhor”, "ganhe destaque”. Talvez por isso haja essa tentativa de resgatar a família como base nos livros do século XXI, mesmo que se deva deixá-la eventualmente, por exemplo, com a possibilidade de ida aos Jogos Vorazes.

Nestes livros, o círculo social também é bastante valorizado, para além dos ambientes de trabalho, podendo serem vistas conexões também nos momentos de lazer.

\footnotetext{
${ }^{3}$ Em tradução livre: "Uma associação de lar com uma vida privada e familiar era importante para ambos homens e mulheres Para um homem, lar era 'o lugar onde se está na companhia da pessoa ou pessoas que mais se ama'. Uma oradora observou que 'Você nunca percebe o que lar realmente significa para você até que se encontre um e crie sua própria família. Para nós significa tudo, segurança, felicidade, camaradagem', enquanto outra afirmou que 'Lar é o lugar onde eu mantenho minha família segura e abrigada e privada."'
} 
Um dos motivos para isto talvez seja o cenário de competição vivido na pós-modernidade (retratado também nas obras através dos Jogos Vorazes), e a necessidade de mostrar que mesmo em meio a tanta rivalidade é importante ter amigos com quem se pode contar em meio às adversidades.

\subsubsection{Vida amorosa}

No que tange o amor romântico e sua relação com as permissões e proibições políticas nestas obras literárias, é possível ver diferentes quadros. Em Fahrenheit 451 (BRADBURY, 2014), não há passagens que denotem algum caráter romântico no personagem de Montag, enquanto em 1984 (ORWELL, 2015), a relação amorosa entre Julia e Winston é o que os leva à ruína.

De início, Winston odeia Julia, mas porque projeta nela seu ódio contra o partido, já que esta, fisicamente, simboliza-o através de sua juventude e sua faixa escarlate em torno da cintura, representando a escolha por castidade. Porém, após receber dela, de forma sorrateira para não ser captada pelas teletelas, um papel onde esta dizia lhe amar, Winston é encorajado a aproximar-se da moça: "A visão das palavras amo você fizera transbordar nele o desejo de continuar vivo, e a ideia de correr riscos menores pareceulhe de repente uma burrice" (ORWELL, 2015, p. 133).

Como relacionamentos são proibidos em Oceânia, a união sexual do casal começa como um ato de rebeldia contra o Partido: "Nenhuma emoção era pura, pois tudo estava misturado ao medo e ao ódio. A união dos dois fora uma batalha; o gozo, uma vitória. Era um golpe assentado contra o Partido. Um ato político" (ORWELL, 2015, p. 153). Porém, após algum tempo de convivência revela-se uma afeição genuína entre os dois personagens.

É justamente esta afeição que sentem um pelo outro que os deixa descuidados, pois ao alugarem um quarto do bairro do proletariado, dividirem seus ideais e irem atrás da Confraria, grupo rebelde oposto ao Socing, estão lidando diretamente, sem saberem, com a Polícia do Pensamento. Ao serem questionados por O'Brien, membro do Partido que finge ser da Confraria, se para fazer parte desta, eles estariam dispostos a nunca mais se verem e responderem negativamente, eles põem em risco não só seu relacionamento como suas vidas.

Embora haja sentimento entre Winston e Julia, não há romance, propriamente dito, trata-se de duas pessoas unidas em seus ideais políticos e com a necessidade de 
permanecerem juntas. Para Winston, que teme deixar de ser humano e tornar-se um autômato sem sentimentos, se apenas confessasse ao Partido suas ações ilegais com Julia, não estaria traindo-a: "Não me refiro à confissão. Confissão não é traição. O que você faz ou diz não importa: o importante são os sentimentos. Mas se eles conseguirem me obrigar a deixar de amar você... Isso sim, seria traição" (ORWELL, 2015, p. 199).

E é justamente desta forma que o governo mina o relacionamento entre eles, colocando-os um contra o outro. O Partido não apenas mata os seus traidores, como os "reeduca", de modo que acreditem fielmente em sua doutrina para, só depois serem eliminados e, como relações amorosas estão fora de seus preceitos, é impossível que os sentimentos de Winston e Julia continuem a existir.

Porém subitamente compreendera que no mundo inteiro só havia uma pessoa
a quem poderia transferir seu suplício - um corpo que teria condições de
interpor entre si e os ratos. E, fora de si, começou a gritar freneticamente.
"Ponha a Julia no meu lugar! Faça isso com a Julia! Não comigo! Com a Julia!
Não me importa o que aconteça com ela. Deixe que esses ratos estraçalhem o
rosto dela, que a roam até os ossos. Eu não! Julia! Eu não!" (ORWELL, 2015,
p. 333).

Nas novas distopias aqui estudadas não existe a proibição do amor como regra geral entre os governos. Na trilogia de Collins, o romance se dá entre Katniss Everdeen, personagem principal, e Peeta Mellark, seu colega de distrito, como forma de gerar popularidade para os dois, garantindo que conseguirão bons patrocinadores e apoio popular durante os jogos.

Katniss e Peeta são manipulados desde o início, por seus mentores, que os estimulam, desde a primeira aparição pública, a mostrarem-se como aliados, e não adversários, o que contraria as normas. Logo em sua entrevista televisionada inicial, Peeta se revela apaixonado por Katniss, que é convencida de que se trata apenas de uma jogada para deixá-los mais atraentes aos olhos do público.

\footnotetext{
- Mas nós não somos amantes desafortunados! - retruco. Haymitch segura meus ombros e me encosta contra a parede. - Quem se importa? Isso aqui é um grande espetáculo. O que importa é como você é percebida. O máximo que eu poderia dizer sobre você depois de sua entrevista é que você era uma pessoa legal, embora isso já fosse um pequeno milagre por si só. Agora posso dizer que você destrói corações. Oh, como os garotos lá do seu distrito caem aos seus pés. Qual vocês acham que vai receber mais patrocinadores? (COLLINS, 2010, p.149).
}

As regras para vitória dos Jogos mudam: antes, apenas uma pessoa poderia sair vitoriosa, mas nesta edição, graças aos "amantes desafortunados" interpretados genuinamente por Peeta e menos convincentemente por Katniss, dois participantes poderão vencer, desde que sejam do mesmo distrito. "Para dois tributos terem o direito 
de sentir o gostinho da vitória, nosso 'romance' deve estar tendo uma repercussão tão grande junto ao público que condená-lo colocaria em xeque o sucesso dos Jogos. Não graças a mim" (COLLINS, 2010, p. 265)

Porém, ao ir atrás de Peeta na reta final do programa, cuidar e protegê-lo, Katniss percebe que nutre sentimentos por ele também, e que já não pode mais perdê-lo: "Por um momento, estou sentindo uma felicidade quase tola, e então uma atrapalhação total toma conta de meu ser. Porque nós deveríamos estar inventando essa coisa toda, representando nosso amor, e não nos amando de fato" (COLLINS, 2010, p. 323).

Desenrola-se então o momento de maior drama dos Jogos Vorazes: após restar apenas os dois tributos do distrito 12 na competição, o que deveria marcar seu fim, um novo anúncio é realizado, dizendo que a decisão anterior havia sido revogada e só poderia haver um campeão. Desta forma, Katniss incentiva Peeta a cometerem um duplo suicídio, ao comerem uma fruta envenenada, pois se os dois juntos não vencessem esta edição, ninguém venceria.

Ao permitir este artifício que vai contra todo o seu esquema político, o presidente Snow percebe o ato de rebeldia e, para evitar que este seja interpretado da mesma maneira por pessoas dos distritos, exige que a relação iniciada pelo casal seja mantida. Assim, eles são obrigados a declarar publicamente seu "amor" como forma de isentá-los da responsabilidade por suas ações.

Ao fim dos Jogos, a população da Capital, porção alienada e fútil de Panem se envolve com hipótese do casamento entre Katniss e Peeta, ajudando a escolher um vestido se tornando também parte do espetáculo. Mas ao regressar ao seu distrito, a moça retorna à sua vida normal, com sua mãe, irmã e caçando com seu amigo Gale, deixando Peeta de lado.

\begin{abstract}
Como fui estúpida em pensar que a Capital simplesmente me ignoraria assim que voltasse para casa! Talvez eu não soubesse nada sobre os potenciais levantes. Mas sabia que eles estavam zangados comigo. Em vez de agir com a extrema cautela que a situação exigia, o que foi que eu fiz? Do ponto de vista do presidente, ignorei Peeta e ostentei minha preferência pela companhia de Gale diante de todo o distrito. E, ao fazer isso, deixei bem claro que estava, na realidade, fazendo pouco da Capital. Agora havia deixado Gale em perigo, e sua família e minha família e Peeta também, em função da minha falta de cuidado (COLLINS, 2011, p. 36).
\end{abstract}

Como punição, em edição comemorativa dos Jogos Vorazes, o presidente manda para arena apenas vitoriosos em edições passadas, culminando com a volta de Peeta e Katniss para arena. Mas esta ação tem um efeito negativo sobre a população da Capital: eles, que já haviam se afeiçoado aos vitoriosos, acham crueldade do governo, o que ajuda 
a pô-lo em xeque, especialmente após a falsa declaração de Peeta que Katniss estaria grávida. É apenas após a derrubada do poder e dos acontecimentos do último volume da trilogia que o casal pode viver seus sentimentos de forma completa e despreocupada.

Já na trilogia de Ally Condie (2011), todos os relacionamentos entre casais são formados pelo governo, levando mesmo ao banimento (ocorrido de forma velada) àqueles que amavam as pessoas "erradas". Apesar disso, demonstra-se a existência de amor entre os casais formados compulsoriamente, como os pais da personagem principal, Cassia Reyes.

Quando nos sentamos para jantar, minha mãe abraça ele e pousa a cabeça no seu ombro por um momento, antes de lhe entregar a embalagem de alumínio. Ele estende a mão para tocar no seu cabelo, no seu rosto. Ao observá-los, penso que algum dia algo parecido pode acontecer a mim e a Xander (CONDIE, 2011, p. 76).

Os casais são estabelecidos e divulgados no Banquete do Par, quando os participantes têm 17 anos, e quem escolher ter um Par terá seu Contrato Matrimonial aos 21 anos para procriar aos 24, em média, aumentando a probabilidade de gerar filhos saudáveis. Cassia foi designada no Banquete ao seu melhor amigo de infância, Xander, porém, ao checar novamente seu microcartão, vê outro rosto, o de seu vizinho Ky.

Este erro é o suficiente para que Cassia veja Ky com outros olhos, passando a ter sentimentos por ele. A recusa em aceitá-los vem da naturalização das regras impostas pela Sociedade, que a fazem crer que apenas seguindo as normas estará em segurança. "Se não tivesse havido um erro, eu só teria visto o rosto dele e tudo seria normal, nada disso teria ocorrido. Eu não teria me apaixonado por Ky e a escolha, na classificação, não teria sido tão difícil” (CONDIE, 2011, p. 196).

O Banquete do Par é a cerimônia mais importante: "Os Pares são o que torna as outras cerimônias possíveis; é o coroamento da Sociedade" (CONDIE, 2011, p. 26). Por isso que em um levante rebelde do grupo chamado Insurreição, é realizado um ataque cibernético nas configurações dos dados, para aumentar a margem de erro e mostrar que a Sociedade também é passível de erros.

A trilogia de Ally Condie se apoia no direito, que se deveria ter, à liberdade de escolha e afetiva, uma vez que sentimentos são o que nos mantém humanos, como percebe Winston (ORWELL, 2015). Sem eles seríamos apenas peças de um maquinário político e, por isso, justifica-se que nas sociedades distópicas estudadas os governos autoritários temem sua manifestação, seja na forma de compaixão, indignação ou amor. 
Por se tratarem de obras ficcionais retratando regimes totalitários, torna-se mais fácil culpar uma única figura ou órgão por todo o controle da subjetividade e influência na vida privada, seja ele o Grande Irmão ou o Presidente Snow, por exemplo. Mas na realidade, diversas sociedades de diversas épocas vêm fazendo esse monitoramento da vida pessoal de diferentes formas, sejam elas leis e normas, sejam convenções e fatos sociais.

Atualmente, com a constante vigilância empreendida por sistemas de câmeras onipresentes e o uso frequente das redes sociais é ainda mais perceptível como influências externas podem interferir em campos privativos íntimos. Como Katniss e Peeta, vemos pessoas viverem de sua imagem na tentativa de agradar um público a fim de obter reconhecimento, sem necessariamente exercer sua liberdade individual e agir conforme suas escolhas.

\footnotetext{
Deitada na cama, com o corpo e a alma machucados e cansados, percebo que os Funcionários têm razão. Assim que você deseja alguma coisa, tudo muda. Agora eu quero tudo. Mais e mais e mais. Quero escolher meu trabalho. Casar com quem eu escolher. Comer torta no café da manhã e correr numa rua de verdade, não num rastreador. Ir rápido quando quiser, e devagar quando quiser. Decidir quais são os poemas que eu quero ler e quais as palavras que quero escrever. Há tanta coisa que eu quero. Sinto isso com tanta intensidade que sou água, um rio de quereres, recolhido na forma de uma garota chamada Cassia (CONDIE, 2011, p. 196).
}

A história criada por Condie vai além de relacionamentos amorosos juvenis: ela o usa como parâmetro para elucidar o questionamento e a não conformidade com padrões socialmente impostos sobre como se comportar, trabalhar, casar, comer e viver. Padrões estes colocados para docilizar corpos e que se dão, muitas vezes, através de ausência ou controle de informações, sem que se perceba claramente quando se está reproduzindo-os.

\section{Considerações finais}

As distopias são consideradas críticas por abordarem temas como vigilância e controle, indiferenciação subjetiva e massificação cultural, aspectos já existentes no presente, porém potencialmente danosos em um futuro próximo (HILÁRIO, 2013). Enquanto a utopia idealizada no século XVI buscava a reparação das imperfeições sociais, confiante em um futuro melhor, as distopias do século XX intencionam amedrontar seu público a partir de ideias que já se encontram em curso.

Por isto, o objetivo deste trabalho foi analisar as obras literárias já citadas anteriormente em seus aspectos sociais e ideológicos, buscando exemplos nas sociedades 
em que se inserem. Assim, percebe-se que a literatura constitui uma forma de expressão de seu cenário de origem, representando deste modo uma comunicação de massa passível da análise de conteúdo (WOJCIEKOWSKI, 2009).

$\mathrm{Na}$ época da primeira onda distópica, o fim da década de 1940 e passadas as duas grandes Guerras Mundiais, o mundo passa por grandes mudanças econômicas, tecnológicas, com a aparição das grandes máquinas, e sociais, o que se reflete nas vidas privadas. A vida nas fábricas e a necessidade de reerguer o primeiro mundo leva à busca pelo reestabelecimento das famílias e vidas domésticas, a um impulso consumista e a uma limitação às interações sociais.

A primeira característica é observada principalmente em 1984, uma vez que as famílias se formam apenas com o objetivo de manter o Partido no poder. Já em Fahrenheit 451 vê-se mais claramente o impulso consumista através da esposa de Montag, que chega a considerar os atores vistos na televisão como sua família. Porém, uma característica presente em ambas as obras é a ausência de laços afetivos entre os familiares e de laços sociais, de modo a manter apenas a "camaradagem" entre os cidadãos.

A distopia, nestes livros, empreende seu maior papel: um sinal de alerta para o que os autores consideravam errado no momento e que tenderia a se tornar pior com o tempo. Porém, nos romances atuais distópicos, o alerta ainda ressoa sobre as mesmas questões: o distanciamento das relações sociais físicas, enquanto há a aproximação virtual (nem sempre tão profunda e verdadeira) e a presença constante de telas tecnológicas monitorando os indivíduos.

Porém, na contramão do século passado, o século XXI produziu livros que valorizam laços familiares e o afeto entre eles, além do círculo social, com quem não compartilha apenas obrigações, mas anseios e descontrações. A mensagem que estas autoras (Collins e Condie) parecem querer passar é que mesmo em um mundo de competições e estruturas pré-determinadas para cada indivíduo, é importante ser fiel aos próprios ideais e ter pessoas com quem se pode contar.

Ambas as trilogias produzidas neste início de século e aqui abordadas não apresentam uma solução para os problemas presenciados, não ousam propor uma utopia para opor-se à sua distopia. Seu objetivo principal é a crítica: denunciar as atrocidades cometidas no passado, já alertadas por Bradbury e Orwell, mas que se mantém em curso até o presente, ainda causando desconforto.

O propósito destas obras é atingir um público anteriormente inalcançável com as outras literaturas distópicas: os adolescentes e jovens adultos. $\mathrm{O}$ fato de ainda serem 
produzidas distopias mostra que ainda há inconformidade com o rumo bárbaro que o mundo está tomando, de modo a incutir nestes jovens o pensamento crítico, para que possam questionar assuntos como sua própria autonomia e o impacto de suas ações no âmbito social e global.

\section{Referências}

BARDIN, L. Análise de Conteúdo. $3^{\text {a }}$ reimpressão da 1. ed. São Paulo: Edições 70, 2016.

BRADBURY, R. Fahrenheit 451. 3. ed. São Paulo: Globo de Bolso, 2014.

COELHO, T. O que é utopia. 2. ed. São Paulo: Editora Brasiliense, 1986.

COLLINS, S. Jogos Vorazes. 1. ed. Rio de Janeiro: Rocco Jovens Leitores, 2010.

COLLINS, S. Em Chamas. 1. ed. Rio de Janeiro: Rocco Jovens Leitores, 2011.

CONDIE, A. Destino. 1. ed. Rio de Janeiro: Objetiva, 2011.

FOUCAULT, M. O que é um autor? 3. ed. Lisboa: Veja. (col. Passagens), 1992.

FROMM, E. Epílogo. In: ORWELL, G. 1984. 26ª reimpressão da 1. ed. São Paulo: Companhia das Letras, 2015.

HILÁRIO, L. C. Teoria crítica e literatura: a distopia como ferramenta de análise radical da Modernidade. Anu. Lit., Florianópolis, v.18, n. 2, p. 201-215, 2013.

LANGHAMER, C. The Meanings of Home in Postwar Britain. Journal of Contemporary History, London, v. 40, n. 2, p. 341-362, 2005.

NEUMANN, A. L.; SILVA, T. A. C.; KOPP, R. Comunicação e educação na literatura distópica: de Nós (1924) a Jogos vorazes (2008). Revista Jovens Pesquisadores, Santa Cruz do Sul, v. 3, n. 1, p. 80-96, 2013.

ORWELL, G. 1984. 26ª reimpressão da 1. ed. São Paulo: Companhia das Letras, [1949] 2015.

PAVLOSKI, E. 1984: a distopia do indivíduo sobre controle. 2005. 276 f. Dissertação (Mestrado em Concentração es Estudos Literários) - Instituto de Letras, Universidade Federal do Paraná, Curitiba, 2005.

SILVA, G. M. R. Leitores vorazes: Literatura jovem e distopia no mundo atual. 2014. $122 \mathrm{f}$. Monografia (Pós-Graduação em Literatura Infantojuvenil) - Universidade Federal Fluminense, Niterói, 2014.

SOARES, J. C.; EWALD, A. P. Reflexões à sombra de Adorno: cultura do consumo, vazio existencial e sofrimento psíquico. Revista Crítica de Ciências Sociales y Jurídicas, Madrid, s.v, s.n, p.1-12, 2004.

WOJCIEKOWSKI, M. M. Utopia/Distopia e Discurso Totalitário: uma análise comparativodiscursiva entre Admirável mundo novo, de Huxley, e A república, de Platão. 2009. 123 f. 
Dissertação (Mestrado em Literatura Comparada) - Instituto de Letras, Universidade Federal do Rio Grande do Sul, Porto Alegre, 2009.

Recebido em: 17 de janeiro de 2018.

Aceito em: 23 de julho 2018. 